\title{
Mercado de carne suína na cidade de São Paulo: segmentos e estratégias
}

\section{Swine meat market in Sao Paulo: segments and strategies}

\author{
Lívia Maria Borges Raimundo' \\ Mário Otávio Batalha ${ }^{1}$
}

\begin{abstract}
Resumo: A identificação das necessidades do mercado consumidor e sua tradução em atributos que melhorem a qualidade de produtos e serviços são fundamentais para gerar e sustentar vantagens competitivas para a indústria de alimentos. Esse processo é vital para a diferenciação de produtos, redução de custos e formulação de estratégias mercadológicas inovadoras. Dessa forma, a realização de estudos que busquem compreender o comportamento do consumidor é importante para a geração de estratégias e táticas que aumentem a competitividade dos agentes de toda e qualquer cadeia produtiva agroindustrial. É através do processo de decisão de compra que o cliente transmite informações sobre os atributos de qualidade que procura em uma categoria de produtos. Nesse contexto, este trabalho tem como objetivo principal estudar o comportamento do consumidor final de carne suína no município de São Paulo, de forma a gerar informações que segmentem esse mercado e possam subsidiar estratégias mercadológicas para as empresas do setor. Para tanto, foi desenvolvido um modelo analítico teórico de comportamento de consumo voltado especificamente para produtos cárneos. Esse modelo forneceu o arcabouço teórico utilizado na condução de um survey junto a 400 indivíduos no município de São Paulo. O tratamento estatístico das informações coletadas permitiu o agrupamento de variáveis explicativas similares de demanda e a investigação de relações de correspondência entre elas. Os resultados mostraram que a carne suína é consumida duas ou três vezes ao mês, tendo sido observado que os homens são consumidores mais frequentes do produto. Já a renda mostrou baixa influência sobre a frequência de consumo, o que indica a importância de fatores extrapreço como determinantes de consumo. A compra de carne suína se dá principalmente em supermercados e os fatores importantes nesse ato são o preço, a aparência e a embalagem da carne. A pesquisa identificou comportamentos de consumo que permitiram agrupar os consumidores em três grupos relativamente homogêneos: os econômicos, os convencionais e os exigentes. Cada um desses grupos possui particularidades em suas variáveis determinantes de consumo. Ao identificar grupos de consumidores com comportamentos semelhantes, o estudo permite que empresas segmentem mercados e estabeleçam estratégias mercadológicas melhor adaptadas a esses mesmos grupos.
\end{abstract}

Palavras-chave: Comportamento do consumidor; Marketing estratégico; Carne suína; Segmentação de mercado.

\begin{abstract}
Identifying the needs of the consumer market and its meaning measured in attributes that improve the quality of products and services is essential to create and maintain competitive advantages within the food industry. This process is vital for product differentiation, cost reduction, and the development of innovative marketing strategies. As follows, studies that seek to understand consumer behavior are important for building strategies and tactics that increase the competitiveness of the actors from any and all agribusiness production chain. By the purchase decision, customers provide information on the quality attributes they are looking for in a category of products. This work aims to study the behavior of final consumers of pork in the municipality of Sao Paulo in order to gather information to segment this market and support marketing strategies for companies within this sector. To this end, a theoretical analytical model of consumer behavior focusing specifically on meat products was developed. This model provided the theoretical framework used to conduct a survey with 400 individuals in Sao Paulo. Statistical analysis of the collected information allowed the grouping of similar demand explanatory variables, as well as the investigation of the correspondence relations among them. The results show that pork is consumed mostly by male individuals two or three times a month. Individual incomes showed little influence on the frequency of consumption, which indicates the importance of extra-price factors as determinants of consumption. Pork is mainly bought in supermarkets, and the important factors involved in the purchase act are the price, appearance and packaging of the meat. The research identified different consumer behaviors that allowed us to classify consumers into three relatively
\end{abstract}

\footnotetext{
${ }^{1}$ Grupo de Estudos e Pesquisas Agroindustriais - GEPAI, Programa de Pós-graduação em Engenharia de Produção - PPGEP, Universidade Federal de São Carlos - UFSCar, Rod. Washington Luís, Km 235, CEP 13565-905, São Carlos, SP, Brasil, e-mail: liviamaria@dep.ufscar.br; dmob@ufscar.br
}

Recebido em Fev. 15, 2014 - Aceito em Abr. 27, 2015

Suporte financeiro: Fundação de Amparo à Pesquisa do Estado de São Paulo - FAPESP. 
homogeneous groups: the economical, the conventional, and the demanding. Each one of these groups has its own peculiarities regarding what directs their consumption. By identifying groups of consumers with similar behaviors, this study allows companies to target markets and establish better marketing strategies adapted to these groups.

Keywords: Consumer behavior; Strategic marketing; Swine meat; Market segmentation.

\section{Introdução e justificativa}

Gerar e sustentar vantagens competitivas são objetivos fundamentais para a sobrevivência de empresas produtoras e processadoras de carne. Diferenciar produtos, reduzir custos, formular estratégias mercadológicas inovadoras e pensar novos modelos de negócios estão entre os principais desafios a serem enfrentados e estratégias a serem seguidas para a consecução desses objetivos. Estudos sobre comportamento do consumidor podem municiar a empresa com informações vitais para a tomada de decisões estratégicas corporativas acertadas. Trata-se de identificar quais as necessidades implícitas e explícitas de um dado mercado consumidor e traduzir essas informações em atributos que melhorem a qualidade de produtos e serviços destinados a esse mesmo mercado.

A determinação das reações dos consumidores em larga escala pode fornecer evidências para melhor atender o mercado. Ngapo et al. (2007a) afirmam que o principal desafio da indústria de carne suína é se tornar mais orientada ao consumidor, o que contribui para justificar a importância do estabelecimento das demandas dos consumidores por esse produto. Os produtores de carne suína, que usualmente se esforçavam para melhorar o desempenho produtivo, mensurado em termos de quantidade e preço do produto final, são agora incentivados a incrementar a qualidade da carne produzida. Isso porque, na atual economia global e competitiva, esse fator é vital para o sucesso dos agentes econômicos envolvidos na produção e distribuição desse produto.

Além de desempenhar papel importante na cultura alimentar do consumidor brasileiro, o agronegócio de carnes suínas é relevante para a economia nacional. O Brasil possui o quarto maior rebanho de suínos do mundo, sendo que $74 \%$ da carne produzida a partir desse rebanho é consumida no mercado doméstico. Apesar desse quadro, dados da FAO (2012) apontam que o consumo anual de carne suína per capita no Brasil é menor (apenas 12 quilos) do que aqueles observados para as carnes de frango e bovina (cerca de 35 quilos por habitante/ano cada uma). Por ser a carne menos consumida em nível nacional, quando comparada às carnes bovina e de frango, ela é justamente aquela que possui maior potencial de crescimento de mercado. A quantidade média de carne suína consumida no Brasil é inferior à média mundial, quase cinco vezes inferior à média dos países da União Europeia e cerca de um terço do verificado na China e nos EUA. Assim, parece claro o potencial de expansão de consumo de carne suína no Brasil e a necessidade de elaboração e implementação de políticas públicas e privadas voltadas para a melhor exploração desse potencial.

$\mathrm{O}$ aumento do consumo de alimentos de maior valor agregado possibilitado pelo aumento da renda real do brasileiro e as incertezas de toda ordem que habitualmente envolvem e condicionam a exportação de carnes emprestam uma relevância inconteste ao desenvolvimento do mercado interno de carnes em geral e da carne de suínos em particular. Desenvolver uma demanda interna dinâmica e robusta aumenta a blindagem do setor às vicissitudes do mercado externo. No entanto, isso somente pode ser conseguido a partir de análises do comportamento do consumidor que levem as empresas a desenvolverem e colocarem no mercado produtos e serviços que reflitam as expectativas e necessidades dos consumidores.

Estudos sobre o comportamento do consumidor brasileiro de carne suína são raros na bibliografia especializada brasileira. Produtores e processadores de carne suína ressentem-se da ausência de análises estruturadas e informações sistemáticas sobre os hábitos e necessidades dos consumidores de seus produtos. A identificação e a análise dos atributos da carne considerados importantes pelos consumidores no momento da decisão de compra podem favorecer a formulação e a implementação de estratégias eficazes de produção e apresentação do produto. Pesquisas de mercado são capazes de responder questões que incluem descobertas sobre os anseios e desejos do cliente ou sobre a visão que o consumidor final tem de empresas ou produtos (Raimundo, 2013).

\section{Objetivo}

Este trabalho tem como objetivo principal estudar o comportamento do consumidor final de carne suína no município de São Paulo, de forma a gerar informações que segmentem esse mercado e possam subsidiar estratégias mercadológicas para as empresas do setor. A pesquisa identifica e avalia as atitudes do consumidor final em relação aos atributos de qualidade da carne suína e suas relações com as tendências produtivas a montante dessa cadeia agroindustrial.

Vale destacar que a pesquisa foi feita a partir de um modelo conceitual de comportamento de consumidor adaptado às especificidades dos consumidores de 
produtos cárneos. Esse modelo, construído a partir de uma revisão bibliográfica sobre o comportamento do consumidor de alimentos, forneceu o arcabouço teórico necessário à identificação e análise das variáveis explicativas do comportamento do consumidor de carne suína na cidade de São Paulo. Obviamente que esse mesmo modelo pode e deve ser testado nos casos de outras carnes, notadamente a bovina e a de aves. Isso posto, deve-se considerar que ao se propor e testar um modelo teórico de comportamento de consumidor de produtos cárneos, este artigo traz contribuições teóricas e empíricas importantes ao campo do marketing de alimentos.

\section{O comportamento do consumidor e o consumidor de alimentos}

Nos limites da sua renda monetária, o consumidor organiza suas compras de modo a maximizar a sua satisfação. O consumidor comunica e descreve suas preferências segundo a forma pela qual ordena suas aquisições dentre as várias possibilidades disponíveis e que lhe são possíveis (Lobato, 1975).

De acordo com Solomon (2002, p. 24), o estudo do comportamento do consumidor pode ser definido como o "[...] estudo dos processos envolvidos quando indivíduos ou grupos selecionam, compram, usam ou dispõem de produtos, serviços, ideias ou experiências para satisfazer necessidades e desejos". Ele consiste no estudo dos processos que os indivíduos experimentam ao tomarem decisões que envolvem o emprego de seus recursos para a compra de itens que lhes satisfaçam determinadas necessidades. Existe, portanto, uma vinculação direta entre as variáveis que comandam esse comportamento e as estratégias e propósitos dos profissionais de marketing. Esses profissionais buscam identificar essas necessidades de forma a levar seus potenciais clientes a consumir determinados produtos e serviços.

Kotler (2000) considera que os estudos sobre o comportamento dos consumidores consistem em análises de seleção, compra, uso e descarte de artigos, serviços, ideias ou experiências para satisfazer suas necessidades e desejos. Tais estudos são uma forma de obtenção de informações-chave para o desenvolvimento de novos produtos, para a precificação de produtos, para escolhas quanto aos canais de distribuição e ainda para o estabelecimento de políticas de promoção e publicidade.

Através da compra, o cliente transmite, para toda a cadeia de produção, informações sobre atributos de qualidade que deseja. Dessa forma, o entendimento do seu comportamento passa a ser um elemento estratégico importante para as empresas (Spers, 1998). Quando um consumidor decide comprar um determinado produto, ele está sancionando um conjunto de estratégias empresariais, nos vários segmentos das cadeias produtivas, que fizeram com que aquele produto chegasse até suas mãos.

Nesse contexto, Vargas (2010) considera que a satisfação das necessidades dos consumidores fundamenta todo o marketing moderno, gerando vantagem competitiva ao mesmo tempo em que impacta as cadeias de suprimentos e o valor percebido dos produtos. Assim, o comportamento dos consumidores afetaria os níveis de investimento, tecnologia, renda e emprego, redundando em retração ou crescimento de determinados setores industriais e de serviços.

Gains (1999), escrevendo especificamente sobre o comportamento do consumidor de alimentos, salienta que entender as preferências alimentares dos indivíduos vai muito além de descobrir do que eles gostam ou desgostam, sendo necessário compreender os motivos dessas preferências. Essa compreensão é vital em diversos contextos mercadológicos, tais como marketing, publicidade, desenvolvimento, posicionamento e rastreabilidade de produtos. A indústria alimentar deve conhecer o comportamento dos seus consumidores, a posição do seu produto no mercado e, ainda, as características que distinguem seus produtos frente aos da concorrência. $\mathrm{O}$ autor afirma que a escolha alimentar, fenômeno psicológico com manifestações físicas, consiste de uma série de reações previsíveis e controláveis. Nessa visão, qualquer comportamento relacionado a alimentos deve levar em consideração três elementos: as características intrínsecas ao alimento (cor, sabor, odor, embalagem etc.), aspectos ligados ao consumidor (fatores socioeconômicos e pessoais) e ao contexto ou situação no qual essa interação ocorre (local de compra, conveniência na compra, confiabilidade do local e eventos específicos que motivam compra).

A revisão teórica de diversos modelos de comportamento de consumo de alimentos (Gains, 1999; Conner, 1999; Khan \& Hackler, 1981; Randall \& Sanjur, 1981; Shepherd, 1985; Cardello, 1999; Furst et al., 1996; Fischler, 2003; Oliveira \& Thébaud-Mony, 1997; Amerine et al., 1965; Grunert et al., 1996) permitiu a construção de um modelo para representação do comportamento do consumidor de alimentos que considerou os principais fatores de consumo relacionados ao indivíduo consumidor, ao ambiente onde o alimento é comprado e consumido e às características intrínsecas ao alimento. Esse modelo, representado na Figura 1, elenca as principais variáveis consideradas nos modelos correntes de comportamento do consumidor de alimentos citados anteriormente.

No entanto, cabe destacar que esse modelo foi especialmente adaptado para incluir variáveis específicas com potencial explicativo do consumo de carnes. Assim, variáveis como "tipo de corte" e "textura", por exemplo, são importantes para determinar o comportamento do consumidor de carnes, mas podem não apresentar nenhum poder explicativo do consumo de outros produtos alimentares. 


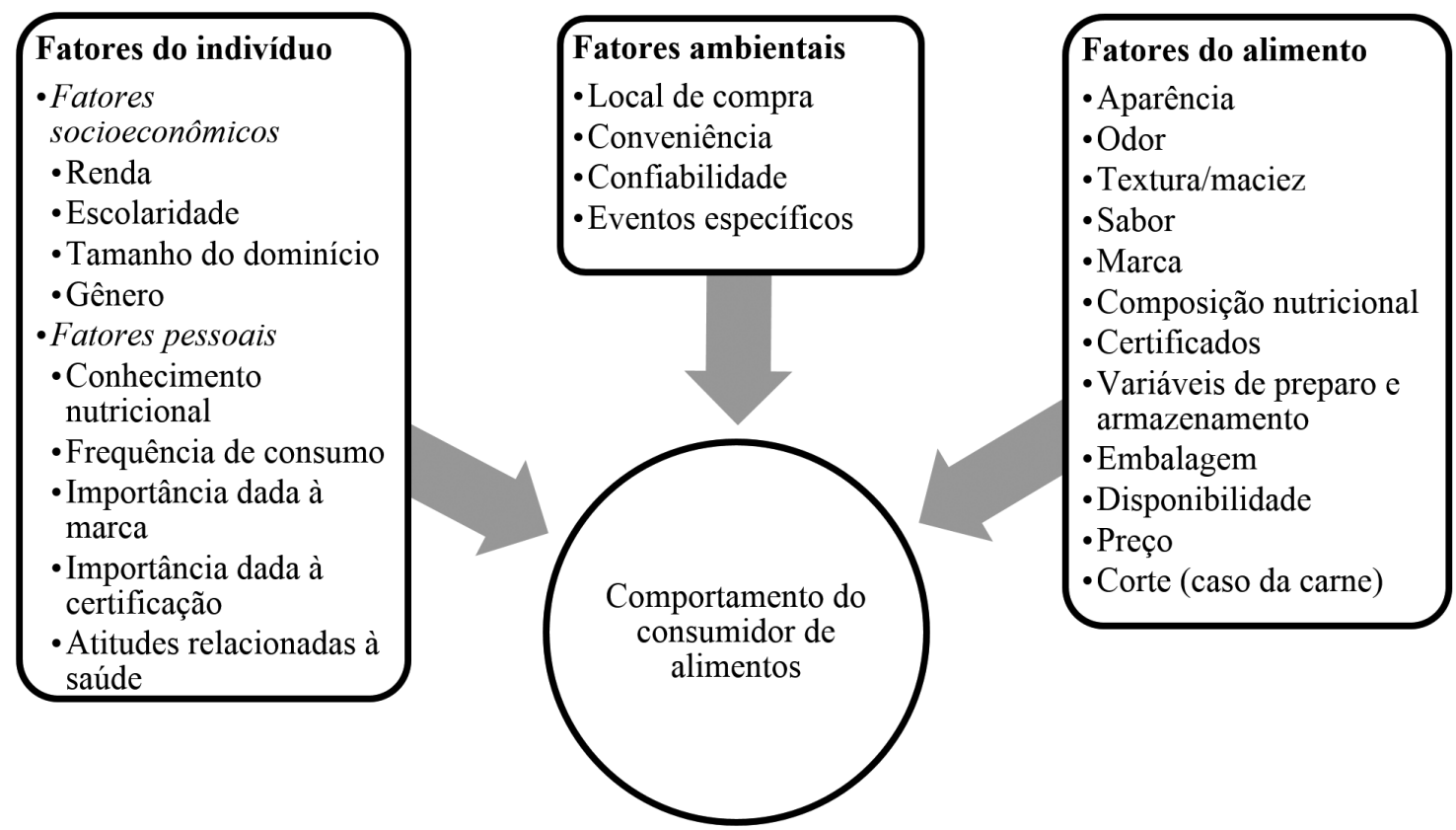

Figura 1. Determinantes do comportamento do consumidor de alimentos. Fonte: Elaborado pelos autores.

\section{$4 \mathrm{O}$ consumo de carne suína no Brasil}

A ingestão per capita de carne suína no Brasil, mesmo tendo crescido significativamente nos últimos dez anos, ainda se mantém bastante inferior à média mundial e também à das carnes bovina e de frango. Dentre os entraves para seu crescimento, constam os altos preços praticados no varejo e, principalmente, a persistência de sua imagem negativa para a saúde do consumidor. Apesar dos avanços em genética e manejo, a carne suína é vista pelo consumidor como um produto rico em gordura e ligado a problemas sanitários. Na região Sudeste do país, a aquisição domiciliar anual per capita do produto foi de aproximadamente seis quilos em 2008, enquanto de carne de frango foram adquiridos cerca de 11 quilos e de carne bovina, 14 quilos (IBGE, 2012).

Estudos nacionais e internacionais (Martins et al., 2009; Bezerra et al., 2007; Couto \& Ferreira, 2005; Faria et al., 2006; Porto, 2004; Ngapo et al. 2007a, b) evidenciam que o consumo de carne suína é efetivamente afetado pelas variáveis que compõem o modelo conceitual apresentado na Figura 1.

Aspectos culturais desempenham um importante papel no consumo alimentar, eles influenciam os tipos de produtos disponíveis em determinados mercados e suas respectivas características, bem como as próprias preferências sensoriais dos consumidores. O estudo de Ngapo et al. (2007a) explorou a preferência dos consumidores de 22 países sobre a cor, o marmoreio - quantidade de gordura intramuscular, que contribui com a suculência e oflavour da carne e seus produtos - e o gotejamento - ou perda de água, que resulta num produto mais pálido - da carne suína no ponto de venda. Em todos os países, a cor foi a característica indicada como mais importante na escolha do produto, com média de $68 \%$ de ocorrência, seguida da camada de gordura. Em geral, a carne magra é a preferida, contudo no Brasil não foi verificada uma preferência consistente nesse aspecto.

Em estudo concomitante, Ngapo et al. (2007b) indicaram que o sabor é o fator mais atrativo na escolha da carne suína frente às carnes concorrentes. No mesmo estudo, o gênero dos entrevistados apresentou a maior influência na escolha da cobertura de gordura da carne. Na maioria dos países investigados, em média 20\% mais mulheres que homens buscam carnes com camadas mais finas de gordura externa, mas não necessariamente não marmorizadas.

O estudo de Ngapo et al. (2007b) indica que 96\% dos consumidores brasileiros declaram gostar da carne suína. Quanto ao local de compra, $68 \%$ dos brasileiros entrevistados compram o produto no supermercado e 54\% realizam compras em açougues. Sobre a frequência de consumo, $56 \%$ dos entrevistados declararam consumir a carne mais de uma vez na semana e 33\%, mais de uma vez no mês. A forma de preparo utilizada pela maior parte dos consumidores é a fritura, seguida da carne assada.

Segundo Bezerra et al. (2007), a carne suína é consumida por cerca de $80 \%$ da população brasileira, sendo seu consumo evitado particularmente por aqueles que a consideram excessivamente gordurosa. Majoritariamente, o consumo se dá apenas quinzenalmente ou de uma ou duas vezes na 
semana, sendo que mais de $90 \%$ dos entrevistados afirmaram ampliar seu consumo nas festas de fim de ano (Couto \& Ferreira, 2005; Faria et al., 2006; Bezerra et al., 2007).

A frequência de homens que consomem carne suína até três vezes por semana é maior que a de mulheres. Para consumidores mais jovens (20 a 29 anos) prevalece o consumo de uma a três vezes por semana, enquanto que entre os mais maduros (na faixa de 40 a 49 anos) predomina o consumo mensal. Esse fato, que pode decorrer do crescimento das preocupações com a saúde, tais como quantidade de calorias e colesterol presentes nos alimentos, com o passar dos anos (Faria et al., 2006).

O corte comercial suíno mais comprado é a bisteca, preferencialmente cortada na hora. Dentre os principais fatores determinantes da compra estão o preço, a aparência, a qualidade da carne e a higiene do local de venda, em detrimento da marca do produto (Bezerra et al., 2007; Faria et al., 2006).

Ressalta-se que o principal local de compra da carne suína é o supermercado. Fatores como vínculos de confiança, variedade de produtos, cortes e tipos de embalagens disponíveis (no caso dos supermercados e boutiques de carne) ou proximidade da residência (no caso de mercados e açougues de pequeno e médio porte) determinam a eleição do local de compra do produto (Bezerra et al., 2007; Faria et al., 2006).

Ao menos $70 \%$ dos consumidores desconhece o significado da rastreabilidade e não procuram saber a origem do produto que estão adquirindo (Faria et al., 2006; Bezerra et al., 2007). Observou-se que a classe socioeconômica interfere diretamente nos níveis de conhecimento e exigência dos consumidores em relação ao produto.

A carne suína se encontra no terceiro lugar da preferência geral dos consumidores brasileiros, precedida pela bovina e de frango. No caso de sua substituição, os consumidores dão preferência para a carne bovina, seguida pela carne de frango. Esse fato está relacionado à tradição e ao sabor da carne bovina, mais parecidos com o da carne suína (Faria et al., 2006; Couto \& Ferreira, 2005).

Alguns estudos apontam uma forte mistificação sobre o consumo da carne suína. A forma de criação e as qualidades sanitária e nutricional representam os maiores questionamentos dos consumidores. Essa situação reforça a importância de ações de divulgação que mostrem os avanços tecnológicos na produção e no controle sanitário da criação de suínos no Brasil. Muitos consumidores ainda acreditam que o consumo dessa carne pode ter impacto negativo na saúde - por transmissão de vermes, problemas inflamatórios, excesso de gordura - e que os animais são criados em péssimas condições de higiene (Bezerra et al., 2007; Couto \& Ferreira, 2005; Faria et al., 2006; Martins et al., 2009).

\section{Métodos}

O universo amostral da pesquisa limitou-se aos consumidores de carne, responsáveis pela decisão da compra do produto, residentes no município de São Paulo. A determinação do tamanho da amostra se deu pela tabela proposta por Mattar (2008, p. 162). Segundo esse autor para uma amostragem representativa de uma população infinita dicotômica, a um erro amostral de 0,05 e uma confiança de $95 \%$, são necessários 400 elementos.

A pesquisa utilizou uma amostra estratificada de caráter probabilístico, de forma que os resultados pudessem ser extrapolados para o resto do universo. Os estratos foram determinados em função da renda e do gênero dos entrevistados, respeitando-se a distribuição da população do município em questão, de forma que a aleatoriedade fosse assegurada. De acordo com dados da Pesquisa Nacional por Amostra de Domicílios (PNAD) do IBGE (2009), a região metropolitana de São Paulo contava com 19,6 milhões de habitantes, dos quais $48 \%$ são homens e 52\% são mulheres. Dos residentes economicamente ativos nessa região, 10,85\% possuem renda de até um salário-mínimo, 33,9\% possuem renda de um a dois salários-mínimos, 14,3\% possuem renda de dois a três salários-mínimos, $12,55 \%$ possuem renda de três a cinco salários-mínimos, 8,25\% possuem renda de cinco a dez salários-mínimos, 3,3\% possuem renda de dez a 20 salários-mínimos, 1,1\% possuem renda de mais de 20 salários-mínimos e, ainda, 15,75\% não possuem rendimento ou não o declararam.

O levantamento quantitativo dos dados foi baseado no modelo de consumo de cárneos criado a partir da revisão bibliográfica (ver Figura 1). Utilizou-se um questionário estruturado do tipo fechado, com perguntas de múltiplas respostas, dividido em cinco partes: pergunta filtro, caracterização do perfil socioeconômico, fatores pessoais, fatores do alimento e caracterização do ambiente. A coleta dos dados foi realizada no município de São Paulo, durante os meses de setembro, outubro e novembro de 2012, e se deu através de entrevistas pessoais, nas quais os consumidores foram abordados em locais públicos de grande fluxo, como praças, parques, terminais rodoviários e pontos turísticos.

Para o tratamento dos dados utilizou-se o pacote estatístico SPSS 19. Primeiramente, foi realizada uma Análise Univariada (estatística descritiva) e, posteriormente, as Análises Multivariadas Fatorial e de Cluster. Essas últimas permitiram o agrupamento de variáveis similares e a investigação da dependência entre variáveis com base nos dados amostrais. $\mathrm{O}$ método hierárquico de Ward foi utilizado para definir o número de grupos considerados na análise. Esse método consiste num procedimento de agrupamento hierárquico que busca unir unidades experimentais a partir da variância, de modo a minimizar o desvio 
padrão entre os dados de cada grupo (Hair et al., 2005). Após a definição do número de clusters, o método não hierárquico $k$-means foi empregado para alocar as unidades experimentais em cada grupo. Em seguida, as características de cada grupo formado puderam ser interpretadas.

\section{Aspectos do comportamento do consumidor de carne suína}

A maior parcela dos entrevistados declarou consumir a carne suína de duas a três vezes por mês - frequências semelhantes às observadas por Faria et al. (2006) e Bezerra et al. (2007). Ainda corroborando o estudo de Faria et al. (2006), o contraste do comportamento para os diferentes gêneros se mostrou muito evidente, uma vez que as mulheres representam $70 \%$ ou mais dos que declararam nunca consumir a carne ou consumi-la no máximo uma vez por mês. Já os homens respondem por mais de $80 \%$ do consumo de três vezes na semana ou mais.

Os respondentes que declararam rendimento de um a dois salários-mínimos mensais compuseram a maioria responsável pelo consumo de três ou mais vezes na semana, fato que pode ser explicado pelos preços mais acessíveis de determinados cortes de carne suína frente aos da bovina. Já a maioria daqueles que declararam nunca consumir o produto é composta pelos consumidores com rendimento entre um e dois ou entre cinco e dez salários-mínimos. Essa constatação permite dizer que, no caso da carne suína, a renda tem baixa influência sobre a frequência de consumo, sendo que não há relação direta entre esses fatores. Não sendo a renda um fator explicativo importante para a escolha desse produto, outros fatores ganham relevância.

A carne preferida pela maior parte dos entrevistados é a carne bovina, seguida pela de frango, cabendo à carne suína a terceira posição. Tal resultado segue o observado por Francisco et al. (2007), Buso (2000), Mazzuchetti $\&$ Batalha (2004), Velho et al. (2009), Porto (2004) e Bezerra et al. (2007). Para os apreciadores de carne suína, a carne bovina é sua melhor substituta, seguida da carne de frango, da mesma forma que observaram Couto \& Ferreira (2005).

A imagem da carne suína é considerada boa para a maior parcela dos respondentes. Dentre os respondentes que afirmaram considerar seu consumo ruim para a saúde, a maior parte possuía desconhecimento nutricional total ou parcial, o principal fator negativo mencionado foi a grande quantidade de gordura presente no produto, o que reforça a necessidade de maior divulgação das qualidades nutricionais da carne suína.

A linguiça é o produto mais comprado pela maior parte dos entrevistados, seguida pelo bacon/torresmo e a bisteca, nessa ordem. O lombo, os demais embutidos de suínos e outros cortes, como a costela, são majoritariamente adquiridos por mulheres, enquanto o pernil, a linguiça e a picanha suína são preferidos pelos homens.

Existe uma relação direta entre renda e qualidade proteica dos produtos consumidos. Embutidos, tais como salsicha, presunto ou similares, a linguiça e cortes como o torresmo, o bacon e a panceta, originários da barriga do porco, são consumidos majoritariamente por respondentes que ganham menos de dois saláriosmínimos por mês. Os que declararam ganhar de dois a três salários-mínimos concentram a maioria do consumo de bisteca, enquanto os que recebem mais de dez salários mensais respondem pela maior parte dos consumidores de carnes mais nobres, como o lombo.

Os principais fatores determinantes na compra da carne suína são o preço, a aparência e a embalagem. Fatores como certificação de qualidade e marca são indiferentes para a maior parcela dos respondentes.

A carne suína é majoritariamente adquirida em supermercados, da mesma forma que o afirmado pela POF 2008-2009 e como observaram Bezerra et al. (2007). A maior parcela dos consumidores que compram a carne suína no açougue realiza as compras nesse local somente "de vez em quando".

Da mesma forma que observado por Mazzuchetti \& Batalha (2004), Bezerra et al. (2007) e Martins et al. (2009), a qualidade dos produtos e a higiene surgem como fatores muito importantes para a escolha do local de compra. A confiança e a variedade dos produtos são consideradas importantes, seguindo o observado por Faria et al. (2006).

\section{Segmentação dos consumidores de carne suína}

A segmentação do mercado permite estabelecer estratégias de intervenção que sejam pertinentes às diversas necessidades, aspirações e demandas dos consumidores, dividindo-os em grupos distintos que justifiquem a adaptação de produtos e serviços.

A partir da análise fatorial e da análise de cluster, foram determinados três agrupamentos de consumidores de carne suína. As 23 variáveis consideradas relevantes para a determinação de segmentos de consumidores e, portanto, consideradas na análise, são apresentadas no Quadro 1 e correspondem a atributos do produto, local de compra e seus atributos (ver Figura 1).

Pela significância das correlações, as variáveis puderam ser agrupadas em oito diferentes fatores, os quais explicam $65 \%$ da variabilidade total dos dados. O Quadro 2 relaciona dos atributos agrupados em cada fator.

Com o objetivo de agrupar os consumidores de acordo com o seu padrão de resposta em relação aos fatores criados pela Análise Fatorial, procedeu-se a uma Análise de Cluster.

Como mostra a Figura 2, para a divisão dos clusters formados em cada etapa de agrupamento utilizou-se o método de Ward. Nota-se que ao se utilizarem dois 
Quadro 1. Variáveis consideradas para a segmentação dos consumidores.

\begin{tabular}{|c|c|c|}
\hline Atributos do produto & Local de compra & Atributos do local de compra \\
\hline Validade & & Localização do estabelecimento \\
Aparência & & Forma de pagamento \\
Preço & Açougue & Qualidade dos produtos vendidos \\
Cor & Supermercado & Atendimento \\
Maciez/textura & Mercearia & Higiene do ambiente \\
Certificado de qualidade & Boutique & Preço \\
Odor & Outros locais & Confiança no fabricante \\
Sabor & & Variedade dos produtos vendidos \\
Embalagem e apresentação & & \\
\hline
\end{tabular}

Fonte: Dados da pesquisa, 2012.

Quadro 2. Fatores para a carne suína.

\begin{tabular}{|c|c|c|}
\hline Fator & Atributos relacionados & Denominação \\
\hline 1 & $\begin{array}{l}\text { Odor; sabor; cor; embalagem e apresentação da carne; } \\
\text { marca; validade; certificado de qualidade. }\end{array}$ & $\begin{array}{c}\text { Características organolépticas, } \\
\text { embalagem e selos. }\end{array}$ \\
\hline 2 & $\begin{array}{l}\text { Preço da carne; preço e forma de pagamento do local de } \\
\text { compra. }\end{array}$ & Preços \\
\hline 3 & Confiança no fabricante; variedade de produtos. & $\begin{array}{c}\text { Estabelecimento de confiança e com } \\
\text { variedade. }\end{array}$ \\
\hline 4 & $\begin{array}{l}\text { Local de compra - açougue e supermercado (atributos } \\
\text { inversamente proporcionais); maciez/textura. }\end{array}$ & Supermercado/açougue \\
\hline 5 & Qualidade dos produtos vendidos; higiene do ambiente. & Estabelecimento de qualidade e limpo. \\
\hline 6 & Localização do estabelecimento e atendimento. & $\begin{array}{l}\text { Estabelecimento bem localizado e com } \\
\text { bom atendimento. }\end{array}$ \\
\hline 7 & $\begin{array}{c}\text { Aparência da carne e mercearia (atributos são } \\
\text { inversamente proporcionais). }\end{array}$ & Aparência da carne \\
\hline 8 & Boutiques e outros locais. & Compra em boutique e outros locais. \\
\hline
\end{tabular}

Fonte: Dados da pesquisa, 2012.

clusters, a homogeneidade entre os grupos é satisfatória, contudo os testes realizados para verificar as diferenças entre os dois clusters com relação aos oito fatores não foram significativos em alguns casos. Devido a esse fato, optou-se por utilizar três clusters.

Determinado o número de clusters, utilizou-se o método não hierárquico $k$-means para obter a melhor distribuição dos indivíduos dentro de cada cluster.

A Tabela 1 apresenta a distribuição socioeconômica dos 400 componentes da amostra, subdivididos nos três agrupamentos formados, bem como as distribuições relacionadas aos seus fatores pessoais em relação à carne suína e à compra de cortes.

\subsection{Grupo 1: Os econômicos}

O cluster dos "econômicos" representa $33 \%$ da amostra. A maior parte de seus indivíduos tem entre 31 e 40 anos de idade, com uma faixa de rendimento familiar mensal de um a dois salários-mínimos. A maioria dos componentes desse grupo declarou possuir o ensino médio completo e residir em total com três pessoas. Em sua maior parte, os consumidores econômicos desconhecem totalmente a composição nutricional da carne suína e consideram seu consumo indiferente sobre a saúde. Ainda nesse grupo, a carne suína é majoritariamente consumida duas ou três vezes no mês, sendo que os cortes mais comprados são a linguiça e o bacon.

O comportamento dos indivíduos econômicos apresenta relação positiva com os fatores 8, 2, 5 e 7 e acentuada relação negativa com os fatores 6 e 3. Dessa forma, pode-se dizer que os consumidores econômicos são os mais sensíveis ao preço da carne suína, bem como à sua aparência e características organolépticas, que incluem sabor, cor e odor. Variáveis como a embalagem, a marca, a validade e o certificado de qualidade também se mostram determinantes na hora da compra.

Esses consumidores preferem realizar suas compras em locais como feiras, mas também frequentam boutiques, supermercados, açougues e mercearias. São muito atentos ao preço e à forma de pagamento 


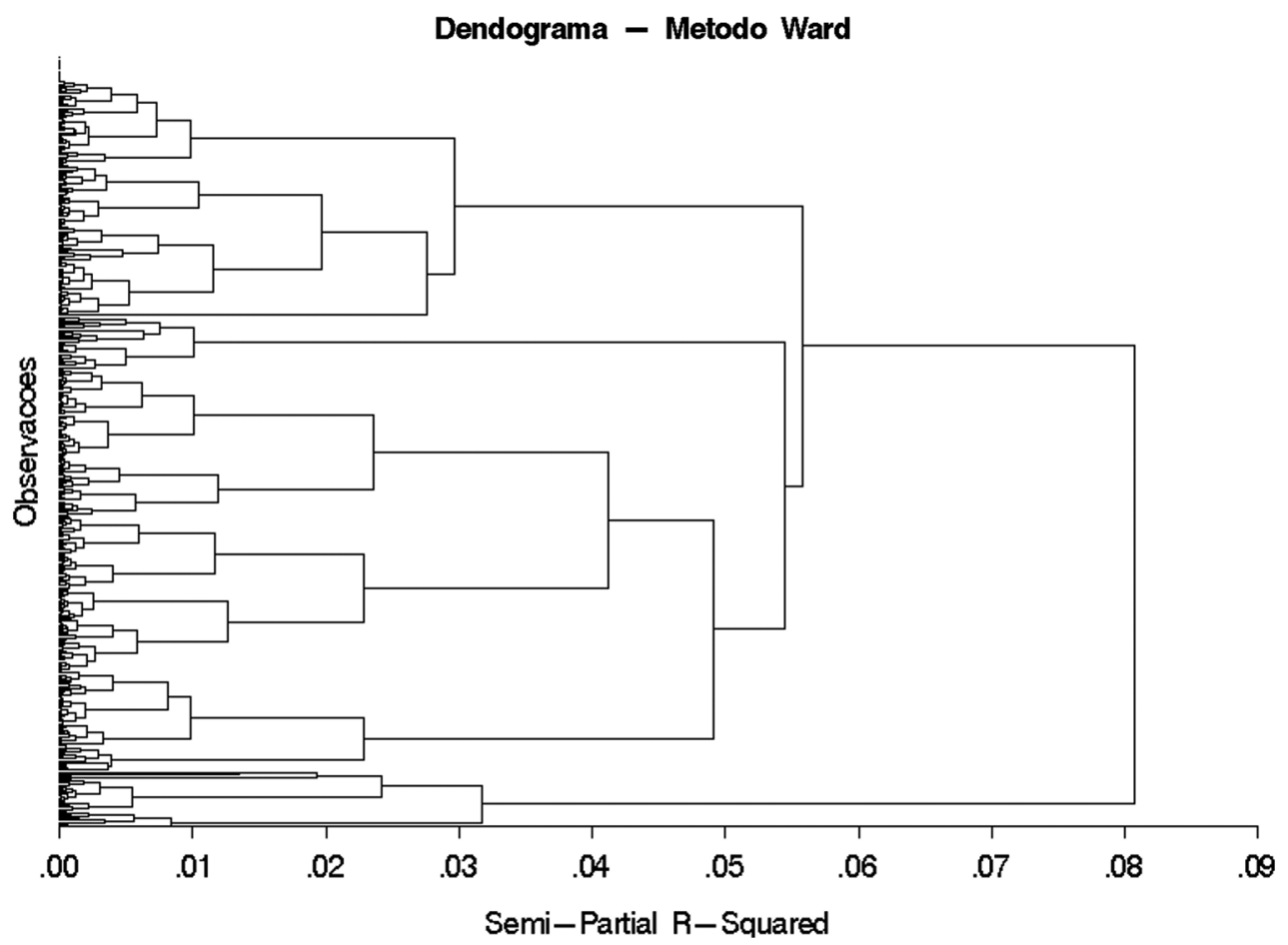

Figura 2. Dendograma - método de Ward. Fonte: Dados da pesquisa, 2012.

dos estabelecimentos que frequentam, bem como à qualidade geral dos produtos vendidos e à higiene do ambiente. Variáveis como a localização do estabelecimento e o atendimento não são importantes, bem como a variedade de produtos e a existência de relação de confiança com o fabricante.

\subsection{Grupo 2: Os convencionais}

O segundo e maior cluster, denominado “convencionais", é formado por $43 \%$ da amostra. É em sua maioria composto por pessoas de 21 a 40 anos. A renda predominante é de um a dois salários-mínimos mensais e a maioria dos domicílios conta com três pessoas. Assim como nos demais grupos, a maior parcela dos respondentes declarou possuir ensino médio completo, sendo que o número daqueles com ensino superior incompleto também é representativo. O consumo da carne suína se dá na maior parte de duas a três vezes por mês e o corte mais consumido é a linguiça, seguida do bacon e da bisteca. A maior parte dos entrevistados considerou não conhecer nem desconhecer a composição nutricional da carne e considerou seu consumo bom para a saúde.

Os consumidores convencionais se relacionaram positivamente com os fatores 2,3 e 6 e negativamente com os fatores 1, 4, 5, 7 e 8. Foram os menos sensíveis à aparência e às características organolépticas (odor, sabor, cor, textura) da carne suína. Para eles, a embalagem, a apresentação da carne, a validade, a marca e a presença de certificado de qualidade na carne não eram importantes.

São os maiores frequentadores de supermercados e mercearias, optando por esses ao invés de açougues e boutiques. Ao escolherem o estabelecimento, foram os que mais levaram em conta a localização e o atendimento, bem como a confiança no fabricante e a variedade de produtos oferecidos. Já a qualidade e a higiene do local não se mostraram importantes.

O preço da carne suína bem como a forma de pagamento oferecida pelo estabelecimento onde adquiriam o produto não sensibilizavam esses consumidores.

\subsection{Grupo 3: Os exigentes}

O grupo dos consumidores exigentes, que conta com $24 \%$ do total de consumidores, é formado, em sua maior parte, por indivíduos de 21 a 30 anos. Dentre os grupos, esse é o que apresenta maior homogeneidade na distribuição de renda em diferentes estratos. A maior parcela de indivíduos desse grupo declarou renda mensal familiar de um a dois salários-mínimos, mas as faixas de renda mais altas também são representativas. A maioria das famílias conta com três ou quatro membros e a maior parte dos componentes declarou ter completado o ensino médio. Esse foi o grupo com maior porcentagem de integrantes que completaram o ensino superior ou uma pós-graduação. O consumo da carne suína 
Tabela 1. Frequências descritivas dos clusters.

\begin{tabular}{|c|c|c|c|c|}
\hline & & $\begin{array}{c}\text { Grupo } 1 \\
\text { Os econômicos (134) }\end{array}$ & $\begin{array}{c}\text { Grupo } 2 \\
\text { Os exigentes (96) }\end{array}$ & $\begin{array}{c}\text { Grupo } 3 \\
\text { Os convencionais } \\
(\mathbf{1 7 0})\end{array}$ \\
\hline \multirow{6}{*}{ Idade } & 18 a 20 anos & $8 \%$ & $4 \%$ & $4 \%$ \\
\hline & 21 a 30 anos & $27 \%$ & $27 \%$ & $29 \%$ \\
\hline & 31 a 40 anos & $33 \%$ & $24 \%$ & $31 \%$ \\
\hline & 41 a 50 anos & $23 \%$ & $20 \%$ & $22 \%$ \\
\hline & 51 a 60 anos & $8 \%$ & $21 \%$ & $9 \%$ \\
\hline & Acima de 61 anos & $2 \%$ & $4 \%$ & $5 \%$ \\
\hline \multirow[t]{6}{*}{ Renda familiar } & Até $1 \mathrm{SM}$ & $18 \%$ & $7 \%$ & $14 \%$ \\
\hline & Mais de 1 até $2 \mathrm{SM}$ & $40 \%$ & $26 \%$ & $39 \%$ \\
\hline & Mais de 2 até 3 SM & $19 \%$ & $16 \%$ & $15 \%$ \\
\hline & Mais de 3 até 5 SM & $9 \%$ & $21 \%$ & $17 \%$ \\
\hline & Mais de 5 até 10 SM & $7 \%$ & $16 \%$ & $12 \%$ \\
\hline & Mais de $10 \mathrm{SM}$ & $7 \%$ & $15 \%$ & $3 \%$ \\
\hline \multirow[t]{8}{*}{ Escolaridade } & Não estudou & $1 \%$ & $1 \%$ & $1 \%$ \\
\hline & $\begin{array}{l}\text { Ensino fund. } \\
\text { Incompleto }\end{array}$ & $13 \%$ & $7 \%$ & $8 \%$ \\
\hline & $\begin{array}{l}\text { Ensino fund. } \\
\text { completo }\end{array}$ & $14 \%$ & $3 \%$ & $16 \%$ \\
\hline & $\begin{array}{l}\text { Ensino médio } \\
\text { incompleto }\end{array}$ & $16 \%$ & $12 \%$ & $14 \%$ \\
\hline & $\begin{array}{l}\text { Ensino médio } \\
\text { completo }\end{array}$ & $25 \%$ & $30 \%$ & $22 \%$ \\
\hline & Superior completo & $16 \%$ & $19 \%$ & $16 \%$ \\
\hline & Superior incompleto & $9 \%$ & $18 \%$ & $19 \%$ \\
\hline & Pós-graduação & $8 \%$ & $10 \%$ & $4 \%$ \\
\hline \multirow{5}{*}{$\begin{array}{l}\text { Pessoas por } \\
\text { domicílio }\end{array}$} & Uma & $7 \%$ & $3 \%$ & $11 \%$ \\
\hline & Duas & $22 \%$ & $21 \%$ & $20 \%$ \\
\hline & Três & $39 \%$ & $33 \%$ & $34 \%$ \\
\hline & Quatro & $28 \%$ & $32 \%$ & $27 \%$ \\
\hline & Cinco ou mais & $5 \%$ & $10 \%$ & $8 \%$ \\
\hline \multirow{5}{*}{$\begin{array}{l}\text { Frequência de } \\
\text { consumo }\end{array}$} & Nunca & $2 \%$ & $4 \%$ & $7 \%$ \\
\hline & $\begin{array}{l}1 \text { vez por mês ou } \\
\text { menos }\end{array}$ & $19 \%$ & $25 \%$ & $18 \%$ \\
\hline & 2 ou 3 vezes por mês & $43 \%$ & $32 \%$ & $37 \%$ \\
\hline & $\begin{array}{l}1 \text { ou } 2 \text { vezes na } \\
\text { semana }\end{array}$ & $33 \%$ & $28 \%$ & $34 \%$ \\
\hline & $\begin{array}{l}3 \text { ou mais vezes na } \\
\text { semana }\end{array}$ & $3 \%$ & $10 \%$ & $5 \%$ \\
\hline \multirow[t]{5}{*}{ Efeito na saúde } & Péssimo & $2 \%$ & $3 \%$ & $4 \%$ \\
\hline & Ruim & $20 \%$ & $29 \%$ & $27 \%$ \\
\hline & Indiferente & $31 \%$ & $23 \%$ & $22 \%$ \\
\hline & Bom & $28 \%$ & $33 \%$ & $34 \%$ \\
\hline & Muito bom & $19 \%$ & $12 \%$ & $13 \%$ \\
\hline
\end{tabular}

Fonte: Dados da pesquisa, 2012. 
Tabela 1. Continuação...

\begin{tabular}{|c|c|c|c|c|}
\hline & & $\begin{array}{c}\text { Grupo 1 } \\
\text { Os econômicos (134) }\end{array}$ & $\begin{array}{c}\text { Grupo } 2 \\
\text { Os exigentes (96) }\end{array}$ & $\begin{array}{c}\text { Grupo } 3 \\
\text { Os convencionais } \\
(\mathbf{1 7 0}) \\
\end{array}$ \\
\hline \multirow[t]{5}{*}{$\begin{array}{l}\text { Conhecimento } \\
\text { nutricional }\end{array}$} & $\begin{array}{l}\text { Desconheço } \\
\text { totalmente }\end{array}$ & $34 \%$ & $14 \%$ & $27 \%$ \\
\hline & $\begin{array}{l}\text { Desconheço } \\
\text { parcialmente }\end{array}$ & $19 \%$ & $16 \%$ & $17 \%$ \\
\hline & $\begin{array}{l}\text { Não conheço nem } \\
\text { desconheço }\end{array}$ & $27 \%$ & $26 \%$ & $28 \%$ \\
\hline & $\begin{array}{l}\text { Conheço } \\
\text { parcialmente }\end{array}$ & $16 \%$ & $32 \%$ & $24 \%$ \\
\hline & Conheço totalmente & $4 \%$ & $13 \%$ & $4 \%$ \\
\hline \multirow{8}{*}{$\begin{array}{l}\text { Corte mais } \\
\text { comprado }\end{array}$} & Lombo & $9 \%$ & $23 \%$ & $9 \%$ \\
\hline & Pernil & $8 \%$ & $7 \%$ & $7 \%$ \\
\hline & Bisteca & $16 \%$ & $18 \%$ & $18 \%$ \\
\hline & Linguiça & $27 \%$ & $25 \%$ & $29 \%$ \\
\hline & $\begin{array}{l}\text { Torresmo/Panceta/ } \\
\text { Bacon }\end{array}$ & $20 \%$ & $10 \%$ & $21 \%$ \\
\hline & Picanha & $2 \%$ & $3 \%$ & $0 \%$ \\
\hline & Embutidos & $16 \%$ & $8 \%$ & $13 \%$ \\
\hline & Outros & $3 \%$ & $5 \%$ & $3 \%$ \\
\hline
\end{tabular}

Fonte: Dados da pesquisa, 2012.

se dá majoritariamente duas ou três vezes no mês e os indivíduos a consideravam boa para a saúde e declararam conhecer parcialmente sua composição nutricional. O corte mais comprado foi a linguiça, seguida do lombo e da bisteca.

Os consumidores exigentes apresentaram forte relação positiva com os fatores $1,4,5,6$ e 7, e relação inversa com os fatores 2,3 e 8 . Assim, pode-se considera-los como os que se apresentaram mais sensíveis às características organolépticas (odor, sabor, cor, textura) da carne suína, bem como à sua embalagem, sua aparência e sua validade. A marca e a certificação de segurança também foram determinantes na hora da compra.

Foram indivíduos que não se afetaram pelo preço do produto, nem mesmo pelo preço ou a forma de pagamento do local onde preferiam realizar suas compras. Suas compras eram preferencialmente feitas em açougues, em detrimento de supermercados, mercearias, boutiques ou outros locais.

$\mathrm{Na}$ escolha do local de compra, foram preferidos aqueles que contavam com maior qualidade de produtos e higiene, melhor localizados e com atendimento satisfatório. Já a confiança no fabricante ou variedade de produtos oferecidos não determinaram a compra.

\section{Considerações finais}

A pesquisa bibliográfica permitiu construir um modelo analítico teórico que elenca as principais variáveis explicativas do comportamento do consumidor de alimentos em geral e, mais especificamente, do consumidor de carnes. Essas variáveis, como deixa supor a bibliografia analisada, referem-se às características intrínsecas ao consumidor, ao alimento em si e ao ambiente no qual o alimento é comprado e consumido. A análise dos resultados da pesquisa quantitativa permite salientar que as variáveis incluídas no modelo aplicado de fato exercem influência sobre o comportamento de consumo de carne suína, de forma que ele possa ser utilizado para o estudo do comportamento de consumo de outras carnes.

Este estudo apresentou o comportamento do consumidor final de carne suína na cidade de São Paulo, o maior centro consumidor do país. Ao identificar grupos relativamente homogêneos de consumidores, o estudo permite que empresas segmentem mercados e estabeleçam estratégias mercadológicas melhor adaptadas a esses mesmos grupos. Os próximos parágrafos fazem um resumo das características de cada um dos três grupos e sugerem estratégias mercadológicas para atendê-los.

A carne suína é principalmente consumida de duas a três vezes por mês. Observaram-se fortes contrastes para os diferentes gêneros, sendo que mulheres representaram $70 \%$ ou mais dos que declararam nunca consumir essa carne ou consumi-la no máximo uma vez por mês. Das que a consumiam mais vezes, algumas declararam consumir o produto mais por gosto da família que por gosto próprio. Já dos respondentes que declararam consumo de três ou mais vezes na 
semana, $80 \%$ eram homens e ganhavam de um a dois salários-mínimos mensais. A renda não se mostrou fator determinante na frequência de consumo de carne suína, sendo que não pôde ser observada relação direta entre esses fatores. Sendo assim, afirma-se que para a compreensão do consumo da carne suína, estudos que priorizem variáveis extrapreço (qualidade, imagem, saúde, segurança alimentar) seriam mais úteis que os que se concentrem em variáveis econômicas (renda e preço).

A segmentação dos consumidores resultou em três perfis distintos de consumidores paulistanos da carne suína: os econômicos, os convencionais e os exigentes (ver Quadro 3).

$\mathrm{O}$ agrupamento dos econômicos apresenta um nível de renda modesto e, portanto, é o mais afetado pelo fator preço (que inclui o preço da carne, o preço do local de compra e a forma de pagamento). Esse fato, entretanto, não os impede de buscar produtos com características organolépticas desejáveis e selos qualificadores (como os de certificação e marca). Esse grupo busca, em geral, estabelecimentos limpos e os que considerem de qualidade. A forma de pagamento facilitada também é determinante para a escolha. Em contrapartida, desconsideram a variedade oferecida pelo local e a relação de confiança com o fabricante. A localização do estabelecimento também não se mostrou relevante. Sendo assim, consumidores econômicos podem ser sensibilizados por melhorias nas características do produto em si (embalagem, aparência, cor, dentre outras) e, principalmente, por promoções de vendas.

Os consumidores convencionais, assim como os econômicos, são influenciados pelo fator preço graças ao seu poder aquisitivo relativamente baixo. $\mathrm{O}$ principal fator de diferenciação entre eles é a importância que dão às características organolépticas, aparência e selos dos produtos no ato da compra, sendo que para esse grupo esses aspectos não são importantes e para aquele eles são relevantes. É um perfil de consumidor tradicional, que tem uma rotina de compra e assim valoriza a relação de confiança existente com o fabricante e a variedade oferecida pelo estabelecimento. Localização favorável e bom atendimento também determinam a escolha do local de compra. Contudo, por confiarem nos locais onde realizam as compras, podem desconsiderar a qualidade dos produtos vendidos ou sua higiene. Como demonstram manter um padrão de compra habitual, acredita-se que eles podem ser influenciados por um aumento da variedade na oferta de produtos e também por promoções de vendas, uma vez que são fortemente influenciados por preços.

Por serem em geral mais abastados que os demais grupos de consumidores, os exigentes são pouco influenciados pelo fator preço (da carne ou do estabelecimento) ou pela forma de pagamento do local de compra. Esse agrupamento se mostra muito atento às características organolépticas dos produtos, bem como à sua aparência e à presença de selos de qualidade. Na escolha do local de compra, buscam locais com boas condições de higiene, bem localizados e que ofereçam bom atendimento. Em contrapartida, consideram irrelevante a existência de confiança no fabricante, bem como a oferta variada de produtos. Por serem muito preocupados com a aparência dos produtos e a higiene do local de compra, podem ser amplamente sensibilizados por investimentos em novas embalagens, certificados como os de origem, de qualidade, de produção orgânica e bem-estar animal, bem como por certificações de boas práticas por parte dos estabelecimentos.

Quadro 3. Agrupamentos e estratégias de sensibilização.

\begin{tabular}{|c|c|c|}
\hline $\begin{array}{l}\text { Agrupamento e } \\
\text { representatividade da } \\
\text { amostra }\end{array}$ & $\begin{array}{l}\text { Principais fatores determinantes } \\
\text { da compra }\end{array}$ & Estratégias a serem adotadas \\
\hline $\begin{array}{l}\text { Econômicos } \\
\qquad(33 \%)\end{array}$ & $\begin{array}{l}\text { - Preços } \\
\text { - Qualidade e limpeza do } \\
\text { estabelecimento } \\
\text { - Aparência da carne }\end{array}$ & $\begin{array}{l}\text { - Melhorias nas características do produto, como } \\
\text { na embalagem, na aparência, na cor etc. } \\
\text { - Promoções de vendas }\end{array}$ \\
\hline $\begin{array}{c}\text { Convencionais } \\
(43 \%)\end{array}$ & $\begin{array}{l}\text { - Preços } \\
\text { - Variedade e confiança no } \\
\text { estabelecimento } \\
\text { - Localização e atendimento }\end{array}$ & $\begin{array}{l}\text { - Aumento da diversificação na oferta de } \\
\text { produtos } \\
\text { - Promoção de vendas }\end{array}$ \\
\hline $\begin{array}{l}\text { Exigentes } \\
(24 \%)\end{array}$ & $\begin{array}{l}\text { - Características organolépticas, } \\
\text { embalagem e selos } \\
\text { - Qualidade e limpeza do } \\
\text { estabelecimento } \\
\text { - Localização e atendimento } \\
\text { - Aparência da carne }\end{array}$ & $\begin{array}{l}\text { - Investimento em novas embalagens, } \\
\text { certificados (de origem, de qualidade, de } \\
\text { produção orgânica e de bem-estar animal) } \\
\text { - Certificações de boas práticas nos } \\
\text { estabelecimentos }\end{array}$ \\
\hline
\end{tabular}


Ao término desta pesquisa, percebeu-se claramente a carência de pesquisas nacionais aprofundadas sobre o consumidor de produtos cárneos. Fazem-se necessários estudos que busquem compreender cada vez melhor a percepção dos consumidores sobre determinados atributos da carne suína em si, a relação entre consumo e status social, o impacto causado pelas características do local de aquisição dos produtos e também a percepção sobre as novas tendências produtivas (como certificados de qualidade, diversificação de embalagens, produção orgânica, dentre outras).

As limitações do trabalho incluem a impossibilidade de controlar a sinceridade dos indivíduos ao responder às questões e também possíveis alterações no comportamento dos consumidores relacionadas a fatores incontroláveis. Em pesquisas desse tipo, muitas vezes o entrevistado possui motivações que o levam a comunicar um comportamento que ele julga mais correto e não aquele que ele efetivamente assume. Variações na economia, problemas de oferta dos produtos e preço ofertado são aspectos que podem modificar a opinião e o poder de decisão dos consumidores para determinados produtos durante um determinado período de tempo. Ressalta-se ainda que mais perguntas poderiam ter sido incluídas para uma identificação precisa do comportamento estudado, contudo, principalmente por limitações de tempo, não foram abordadas de forma mais aprofundada preferências por diferentes tipos de embalagens, diferentes cores dos produtos, diferentes selos de certificação, questões sobre a disposição dos produtos nos pontos de venda, dentre outros aspectos.

Esse tipo de pesquisa pode balizar estratégias empresariais, refletindo-se nas técnicas de gestão de empresas produtoras e varejistas, melhorando seu desempenho e sua competitividade na cadeia produtiva de carne suína e, ainda, estimulando seu consumo no país.

\section{Agradecimentos}

Agradecemos à Fapesp pelo financiamento desta pesquisa, sem o qual o presente trabalho não teria sido possível.

\section{Referências}

Amerine, M. A., Pangborn, R. M., \& Roessler, E. B. (1965). Principles of sensory evaluation of food. New York: Academic Press.

Bezerra, J. M. M., Cavalcante Neto, A., Silva, L. P. G., Lui, J. F., Rodrigues, A. E., \& Martins, T. D. D. (2007). Caracterização do consumidor e do mercado da carne suína na microrregião de campina grande, estado da Paraíba. Ciência Animal Brasileira, 8(3), 485-493.

Buso, G. (2000). Análise do perfil do consumidor de carne bovina na cidade de São Paulo [Dissertação de mestrado
Engenharia de Produção]. Universidade Federal de São Carlos, São Carlos.

Cardello, A. (1999). Consumer expectation and their role in food acceptance. In H. J. H. Macfie \& D. Thomson (Eds.), Measurement of food preferences. London: Chapman \& Hall.

Conner, M. T. (1999). An individualized psychological approach to measuring influences on consumer preferences. In H. J. H. Macfie \& D. Thomson (Eds.), Measurement of food preferences. London: Chapman \& Hall.

Couto, D. L. A., \& Ferreira, A. V. (2005). Avaliação dos determinantes do consumo de carne suína no município de Patos de Minas - MG. p.9.

Faria, I. G., Ferreira, J. M., \& Garcia, S. K. (2006). Mercado consumidor de carne suína e derivados em Belo Horizonte. Arquivo Brasileiro de Medicina Veterinária e Zootecnia, 58(2), 251-256. http://dx.doi.org/10.1590/ S0102-09352006000200014.

Fischler, C. (2003). Manger, une pratique culturelle: le paradoxe de l'abondance. Sciences Humaines (135).

Food and Agriculture Organization of the United Nations FAO (2012). Recuperado em 20 de novembro de 2012, de http://faostat.fao.org

Francisco, D. C., Loguercio, A. P., \& Camargo, L. (2007). Caracterização do consumidor de carne de frango da cidade de Porto Alegre. Ciência Rural, 37(1), 253-258.

Furst, T., Connors, M., Bisogni, C. A., Sobal, J., \& Falk, L. W. (1996). Food choice: a conceptual model of the process. Appetite, 26(3), 247-265. http://dx.doi. org/10.1006/appe.1996.0019. PMid:8800481.

Gains, N. (1999). The repertory grid approach. In H. J. H. Macfie \& D. Thomson (Eds.), Measurement of food preferences. London: Chapman \& Hall.

Grunert, K. G., Larsen, H. H., Madsen, T. K., \& Baadsgaard, A. (1996). Market orientation in food and agriculture. Dordrecht: Kluwer Academic Publishers.. http://dx.doi. org/10.1007/978-1-4613-1301-4.

Hair, J. F. Jr., Anderson, R. E., Tatham, R. L., \& Black, W. C. (2005). Análise multivariada de dados (5. ed.). Porto Alegre: Bookman.

Instituto Brasileiro de Geografia e Estatística - IBGE (2009). Pesquisa nacional por amostra de domicílios: PNAD. Rio de Janeiro: IBGE. Recuperado em 12 de setembro de 2012, de http://www.ibge.gov.br/home/estatistica/ pesquisas/pesquisa_resultados.php?id_pesquisa=149

Instituto Brasileiro de Geografia e Estatística - IBGE (2012). Recuperado em 12 de setembro de 2012, de http://www.ibge.gov.br/home

Khan, M. A., \& Hackler, L. R. (1981). Evaluation of food selection patterns and preferences. CRC Critical Reviews in Food Science and Nutrition, 15(2), 129-153. http:// dx.doi.org/10.1080/10408398109527314. PMid:7023847.

Kotler, P. (2000). Administração de marketing (10. ed.). São Paulo: Prentice Hall. 
Lobato, J. G. (1975). Elasticidades parciais e totais de demanda e oferta de carnes bovina e suína no mercado brasileiro (Dissertação de mestrado em Economia Rural). Universidade de Viçosa, Viçosa.

Martins, T. D. D., Bezerra, W. I., Moreira, R. T., Silva, L. P. G., \& Batista, E. S. (2009). Mercado de embutidos de suínos: comercialização, rotulagem e caracterização do consumidor. Revista Brasileira de Saúde e Produção Animal, 10(1), 12-23.

Mattar, F. N. (2008). Pesquisa de marketing. (4. ed.). São Paulo: Atlas.

Mazzuchetti, R. N., \& Batalha, M. O. (2004). O comportamento do consumidor em relação ao consumo e às estruturas de comercialização da carne bovina na região de Amerios/ PR. Revista Varia Scientia, 4(8), 25-43.

Ngapo, T. M., Martin, J.-F., \& Dransfield, E. (2007a). International preferences for pork appearance: I. Consumer choices. Food Quality and Preference, 18(1), 26-36. http://dx.doi.org/10.1016/j.foodqual.2005.07.001.

Ngapo, T. M., Martin, J.-F., \& Dransfield, E. (2007b). International preferences for pork appearance: II. Factors influencing consumer choice. Food Quality and Preference, 18(1), 139-151. http://dx.doi.org/10.1016/j. foodqual.2005.09.007.

Oliveira, S. P., \& Thébaud-Mony, A. (1997). Estudo do consumo alimentar: em busca de uma abordagem multidisciplinar. Revista de Saude Publica, 31(2), 201-208. http://dx.doi.org/10.1590/S0034-89101997000200015. PMid:9497569.

Porto, R. G. (2004). Consumidor final de carnes: características e hábitos em Pelotas, RS. Serviço de
Informação da Carne. Recuperado em abril de 2012, de http://www.sic.org.br/PDF/Pesquisa_Pelotas.pdf

Raimundo, L. M. B. (2013). Comportamento do consumidor de alimentos: uma análise do consumo de carnes em São Paulo (Dissertação de mestrado em Engenharia de Produção). Universidade Federal de São Carlos, São Carlos.

Randall, E., \& Sanjur, D. (1981). Food preferences: their conceptualisation and relationship to consumption. Ecology of Food and Nutrition, 11(3), 151-161. http:// dx.doi.org/10.1080/03670244.1981.9990671.

Shepherd, D. (1985). Dietary salt intake. Nutrition \& Food Science, 85(5), 10-11. http://dx.doi.org/10.1108/eb059082.

Solomon, M. R. (2002). O comportamento do consumidor: comprando, possuindo, sendo (5. ed.). São Paulo: Bookman.

Spers, E. E. (1998). Preferência do consumidor por atributos de segurança: aplicação de conjoint analysis (Dissertação de mestrado em Economia Aplicada). Universidade de São Paulo, Piracicaba.

Vargas, A. R. (2010). Comportamento de compra do consumidor no varejo supermercadista: o caso de Mato Grosso (Dissertação de mestrado em Engenharia de Produção). Universidade Federal de São Carlos, São Carlos.

Velho, J. P., Barcellos, J. O. J., Lengler, L., Elias, S. A.-A., \& Oliveira, T. E. (2009). Disposição dos consumidores porto-alegrenses à compra de carne bovina com certificação. Revista Brasileira de Zootecnia, 38(2), 399-404. http:// dx.doi.org/10.1590/S1516-35982009000200025. 